\title{
Afinal, O QUe QUer A MUlHer BRASILEIRA?
}

\author{
Mirian Goldenberg*
}

\section{Resumo}

Neste texto, discuto o papel do corpo como uma importante forma de capital (físico, simbólico e social) na cultura brasileira. Busco revelar os traços distintivos de uma cultura em que o corpo é um elemento crucial na construção de uma identidade nacional. Podese afirmar que, no Brasil, o corpo é um capital, talvez o mais desejado por indivíduos das camadas médias urbanas e também das camadas mais baixas. Isto decorre, provavelmente, da percepção do corpo como um veículo fundamental para a ascensão social, sendo capital relevante nos mercados de trabalho, casamento e erótico.

Palavras-chave: gênero; corpo; capital; casamento; envelhecimento.

\section{Abstract}

\section{WHAT THE BRAZILIAN WOMAN WANTS?}

In this text I discuss the role of the body as an important form of (physical, symbolic, and social) capital in Brazilian culture. I try to lay out the distinguishing traits of a culture in which the body is a crucial element in the construction of a national identity. It can be said that in Brazil the body is a capital, maybe the most desired one by the urban middle class and also lower strata, which perceive the body as a fundamental vehicle for social ascension, and also an important form of capital in the job, spousal, and erotic markets.

Keywords: gender; body; capital; marriage; ageing.

\section{INTRODUÇÃo}

Este texto visa apresentar os principais achados de três grandes pesquisas antropológicas que analisaram as representações, presentes nos discursos de ho-

* Doutora em Antropologia Social; Professora do Departamento de Antropologia Social e do Programa de Pós-Graduação em Sociologia e Antropologia do IFCS/UFRJ. 
mens e mulheres, sobre as mudanças e continuidades nos papéis de gênero na atualidade. Busca-se analisar, comparativamente, as expectativas, os estereótipos, os problemas, os desejos, as paixões, os sonhos, os valores e os comportamentos de mulheres e homens em torno de temas como família, infidelidade, conjugalidade, sexualidade, intimidade e construção social do corpo e do envelhecimento. Logo, pretende-se: (1) verificar as diferenças e semelhanças, os conflitos e contradições presentes nos discursos, no que diz respeito aos modelos de "ser homem" e "ser mulher", com intuito de compreender como ambos estão lidando com as rápidas mudanças que afetam os papéis de gênero; (2) analisar como se dá a convivência entre modelos considerados tradicionais e os "novos" modelos de masculinidade e feminilidade.

A primeira pesquisa foi realizada em 2000, com 1279 homens e mulheres moradores da cidade do Rio de Janeiro, sobre casamento, sexualidade, infidelidade. A segunda pesquisa foi realizada em 2008 e 2009, com 1617 homens e mulheres moradores da cidade do Rio de Janeiro, sobre corpo, envelhecimento e felicidade.

A última pesquisa foi realizada em 2010, com 250 homens e mulheres moradores da cidade do Rio de Janeiro, com o objetivo de discutir o papel do humor, da risada e da felicidade nas relaçôes conjugais, no ambiente de trabalho, nas amizades, entre outros; mas também comparar as diferenças entre homens e mulheres com relação a estas questôes.

Nestas pesquisas procuro retomar temas, com os quais venho trabalhando há mais de vinte anos, através de novo caminho metodológico. Este caminho é suscitado por questôes oriundas das transformações na família e papéis de gênero da sociedade brasileira, particularmente nas últimas três décadas. Com a preocupação de ampliar o espectro da pesquisa sobre gênero, desenvolvida nos estudos anteriores, foram utilizados, além de entrevistas e observação participante, questionários elaborados quanto às seguintes temáticas: representaçôes sobre ser homem e ser mulher; os modelos ideais de casamento; as experiências de relacionamento afetivo-sexuais; entre outras. Esta metodologia se deve à confiabilidade no valor heurístico da combinação da análise estatística do grupo pesquisado com uma abordagem interpretativa (com base nas entrevistas qualitativas). Assim, os diferentes pontos de vista e as novas formas de coleta e análise de dados desta pesquisa poderão contribuir para uma ideia ampla e inteligível da complexidade da relação entre os sexos.

Com os dados das três pesquisas é possível discutir as contradições existentes nas camadas médias urbanas entre comportamentos e valores considerados tradicionais e modernos. Isto contribui para a análise das transformaçōes dos papéis de gêneros e propõe reflexões sobre os novos papéis, as crises de identidade, os novos 
arranjos conjugais, a constituição de novas famílias, constatação da crise de um modelo hegemônico de masculinidade, a coexistência de modelos antigos e novos de conjugalidade, a elaboração de novas formas de ser mãe e mulher, a existência de uma dupla moral com relação à sexualidade feminina e à masculina, as representações sobre o amor, a família e o casamento, as mudanças nas relações entre os sexos e as suas consequências em outros domínios sociais. A partir destas ideias, serão desenvolvidos os principais resultados das minhas três pesquisas para tentar responder à pergunta: afinal, o que quer a mulher brasileira?

\section{O CORPO COMO CAPITAL}

Nos últimos anos, pesquisando homens e mulheres das camadas médias do Rio de Janeiro, elaborei e discuti, em meus livros e palestras, a seguinte ideia: no Brasil, o corpo é um verdadeiro capital. Determinado modelo de corpo, na cultura brasileira contemporânea, é uma riqueza, talvez a mais desejada pelos indivíduos das camadas médias urbanas, bem como das camadas mais pobres. Verifica-se que estas percebem seu corpo como um importante veículo de ascensão social e, também, como um capital nos mercados de trabalho, casamento e sexual.

Neste sentido, além de um capital físico, o corpo é um capital simbólico, um capital econômico e um capital social. No entanto, é preciso ressaltar que este corpo capital não é um corpo qualquer. É um corpo que deve ser sempre sexy, jovem, magro e em boa forma. Um corpo conquistado por meio de um enorme investimento financeiro, muito trabalho e uma boa dose de sacrifício.

A ideia de o corpo como um capital surgiu a partir das minhas pesquisas na cidade do Rio de Janeiro. Ao perguntar às mulheres cariocas "O que você mais inveja em uma mulher?", elas responderam: "beleza em primeiro lugar, o corpo, em seguida, e inteligência em terceiro lugar". Quando perguntei aos homens "O que você mais inveja em um homem?", tive como respostas: "inteligência, poder econômico, beleza e o corpo".

Em outra questão, perguntei às mulheres: "O que mais te atrai em um homem?”. Elas responderam: "inteligência e o corpo". Quando perguntei aos homens "O que mais te atrai em uma mulher?", encontrei: "beleza, inteligência e o corpo". $\mathrm{O}$ corpo aparece ainda com maior destaque quando perguntado às mulheres " $\mathrm{O}$ que mais te atrai sexualmente em um homem?". As respostas foram: "tórax e o corpo". Para os homens: "O que mais te atrai sexualmente em uma mulher?". Tive: "bunda e o corpo". 
Também perguntei: "Se você escrevesse um anúncio com o objetivo de encontrar um parceiro, como você se descreveria? E como você descreveria o que procura em um parceiro?”. Nas respostas, o corpo aparece seguido de inúmeros adjetivos, tais como: "sexy, sensual, atraente, gostoso, definido, malhado, trabalhado, sarado, saudável, atlético, forte, firme, jovem, magro e em boa forma”. A cultura brasileira, particularmente a cultura carioca, a partir da valorização de determinadas práticas, transforma o que é natural, o corpo biológico, em um corpo distintivo: o corpo como capital. Abaixo encontram-se dois exemplos dos anúncios dos pesquisados, que ilustram bem as respostas:

Eu sou magra, jovem, cabelos loiros, longos e lisos, bunda grande, seios durinhos, carinhosa e muito gostosa. Procuro alguém de corpo sarado, másculo e sexy!

Eu sou alto, forte, bem dotado, inteligente e romântico. Procuro uma mulher linda e gostosa, de cabelos longos, peitos fartos, bumbum arrebitado e com um corpo muito sexy.

No Brasil, particularmente no Rio de Janeiro, o corpo trabalhado, cuidado, sem marcas indesejáveis (rugas, estrias, celulites, manchas) e sem excessos (gordura, flacidez) é o único que, mesmo sem roupas, está decentemente vestido. Pode-se pensar, neste sentido, que além de o corpo ser muito mais importante do que a roupa, ele é a verdadeira roupa. Ou seja, é o corpo que deve ser exibido, moldado, manipulado, trabalhado, costurado, enfeitado, escolhido, construído, produzido, imitado. É o corpo que entra e sai da moda. A roupa, neste caso, é apenas um acessório para a valorização e exposição deste corpo capital.

Com a ideia de que o corpo, no Brasil, é um verdadeiro capital, é possível compreender por que as mulheres brasileiras (logo após as norte-americanas) são as maiores consumidoras de cirurgia plástica estética em todo o mundo, além de outros procedimentos para conquistarem esse corpo, tais como: preenchimentos faciais, botox, tintura para cabelo, entre outros.

Pode-se dizer que ter $o$ corpo, com tudo o que ele simboliza, promove nos brasileiros uma conformidade a um estilo de vida e a um conjunto de normas de conduta. Esta é recompensada pela gratificação de pertencer a um grupo de valor superior. $O$ corpo surge como um símbolo que consagra e torna visível as extremas diferenças entre os grupos sociais no Brasil.

Com o título "O corpo que eles desejam... não é o que elas querem ter", a Revista Época (2002) mostrou um fenômeno esquizofrênico da nossa época: mulheres querem seduzir homens com um corpo que está longe da preferência masculina. $\mathrm{O}$ padrão de beleza desejado pelas mulheres brasileiras tem sido construído por meio de imagens das supermodelos, que se consagraram a partir dos anos $1980 \mathrm{e}$ 
conquistaram status de celebridade nos 1990. Doenças como anorexia e bulimia se tornaram quase uma epidemia nos últimos anos, em uma geração que cresceu tentando imitar o corpo de Cindy Crawford, Linda Evangelista, Claudia Schiffer e, mais recentemente, da brasileira Gisele Bündchen. Isto é observado em minha pesquisa (2002), pois os homens que responderam ao questionário elegeram como suas musas: Sheila Carvalho, Luma de Oliveira, Luana Piovani, Mônica Carvalho e outras mulheres. Todas as mulheres eleitas estão muito longe das medidas das modelos das passarelas, modelos que possuem os corpos invejados (e, muitas vezes, imitados) pelas participantes da pesquisa.

Segundo a Sociedade Brasileira de Cirurgia Plástica, o brasileiro se tornou, logo após o americano, o povo que mais faz plástica no mundo: 629.000 brasileiros se submeteram a pelo menos um procedimento cirúrgico em 2008. As mulheres são a esmagadora maioria: 88\%. De 2002 a 2003 cresceu em 43\% o número de jovens que se operam: $13 \%$ do total dos que fazem plástica são jovens de menos de 18 anos. A operação das mamas é a primeira cirurgia mais realizada (33\%), seguida da lipoaspiração (20\%). No quesito insatisfação com o próprio corpo, as brasileiras só ficam atrás das japonesas ( $37 \%$ das brasileiras se disseram insatisfeitas) em uma pesquisa realizada com 3.200 mulheres de dez países. Só 1\% das mulheres brasileiras se acha bonita; $54 \%$ das brasileiras já consideraram a possibilidade de fazer plástica; $7 \%$ já fizeram (índice mais alto entre os países pesquisados). Mas o que torna o Brasil especial nessa área é a rapidez com que a decisão é tomada. São três as principais motivações femininas para fazer uma cirurgia plástica: atenuar os efeitos do envelhecimento, corrigir defeitos físicos e esculpir um corpo perfeito. No Brasil, esta última motivação é a que mais cresce: a busca de um corpo perfeito. Também com relação ao uso de botox e ao implante de próteses de silicone, o Brasil é o segundo no mundo, logo após os Estados Unidos. "Desde 1995, o número de cirurgias para aumentar os seios das brasileiras quintuplicou. Nos últimos dez anos, cresceu $300 \%$ o número de cirurgias nos seios das adolescentes" (Goldenberg, 2007: 57).

A obsessão com determinado modelo de corpo tem atrapalhado a vida sexual de muitos brasileiros, como revelam alguns depoimentos dos meus pesquisados:

Acho minha namorada linda, com o corpo lindo. Acho até engraçado quando ela tenta me mostrar que tem celulite, estria. Eu não consigo enxergar nada. $\mathrm{O}$ mais estranho é que ela não só quer que eu enxergue como quer que eu ache feio. Ela insiste tanto que eu vou acabar achando feio mesmo.

Muitas vezes estamos no meio da transa, no maior clima, e ela pergunta: estou gorda? Ou então insiste em transar no escuro para eu não ver o corpo dela. Perco totalmente o tesão. 
No Rio de Janeiro, onde as praias e a temperatura extremamente elevada (durante quase todo o ano) favorecem o desnudamento, a centralidade que a aparência física assume na vida cotidiana é muito mais evidente. A crença de que o corpo é um capital produz uma cultura de enorme investimento na forma física e, também, de profunda insatisfação com a própria aparência.

O sociólogo Pierre Bourdieu (1999) afirmou, no clássico $A$ dominação masculina, que os homens tendem a se mostrar insatisfeitos com as partes de seu corpo consideradas pequenas demais. Por outro lado, as mulheres dirigem suas críticas às regiōes de seu corpo que lhe parecem grandes demais. $\mathrm{O}$ autor acredita que a dominação masculina, que constitui as mulheres como objetos simbólicos, tem por efeito colocá-las em permanente estado de insegurança corporal, ou melhor, de dependência simbólica: elas existem primeiro pelo e para o olhar dos outros, como objetos receptivos, atraentes, disponíveis. Delas se espera que sejam femininas, ou seja, sorridentes, simpáticas, atenciosas, submissas, delicadas, discretas, contidas, apagadas ou até mesmo invisíveis. Neste caso, ser magra contribui para esta concepção de ser mulher. Sob o olhar dos outros, as mulheres se veem obrigadas a experimentar constantemente a distância entre o corpo real, a que estão presas, e o corpo ideal, o qual procuram infatigavelmente alcançar.

Um exemplo deste tipo de dominação é o que está ocorrendo no Brasil. Milhares de meninas e adolescentes sofrem de anorexia e bulimia. Só em Porto Alegre, não por coincidência uma das capitais em que despontam as modelos brasileiras mais bem-sucedidas internacionalmente, 13\% de adolescentes do sexo feminino sofrem de anorexia ou de bulimia (Goldenberg, 2006). A anorexia e a bulimia parecem ter evoluído da condição de patologia para a categoria de estilo de vida. Inúmeras páginas pessoais na internet divulgam movimentos pró-anorexia e pró-bulimia. São chamadas de "amigas da Ana" e "amigas da Mia”, dando dicas para aquelas que desejam aderir a um estilo de vida que tem a magreza como modelo a ser seguido.

Adolescentes estão usando a internet para ensinar outras jovens a serem anoréxicas e bulímicas, pregando a inapetência e a autopunição sempre que comerem. As páginas são assustadoras, utilizando fotografias de meninas esquálidas apontadas como modelos de beleza, dicas para enganar os pais e amigos para fingir que estão alimentadas e formas de se punir caso comam algo que engorda. Os sites divulgam os seguintes mandamentos: "Você não deve comer sem se sentir culpada", "Você não deve comer algo que engorda sem se punir depois", "Ser magra é mais importante do que ser saudável", "Você nunca está magra", "Ser magra é a coisa mais importante que existe". Outras dicas são: "Não engula! Morda, mastigue e jogue fora!", "Durma pouco. Dessa forma você queima mais calorias", "Limpe banheiros 
ou ambientes bem sujos. Você perde a fome", "Diga que você vai comer no quarto e jogue a comida fora", "Em casa, diga que vai comer com os amigos. Aos amigos você diz que já comeu em casa”.

Por outro lado, dentro da mesma lógica de dominação masculina, os homens são obrigados a serem fortes, potentes e viris. Inúmeros rapazes já morreram no Brasil por consumirem anabolizantes para animais. Um trabalho interessante sobre a obsessão masculina em responder a um ideal de ser homem, ancorado em um corpo musculoso, na performance sexual e no tamanho do pênis é $O$ complexo de Adônis. Seus autores (Pope, Phillips, \& Olivardia, 2000) afirmam que milhões de homens nos Estados Unidos estão sacrificando aspectos importantes de suas vidas para se exercitarem compulsivamente nas academias. Milhões de dólares são gastos em suplementos alimentares e esteroides anabolizantes, que causam câncer, hepatite e outras doenças graves. Além destas drogas perigosas, os distúrbios alimentares são cada vez mais frequentes neste universo. Os mesmos autores revelam, ainda, que mais de um milhão de norte-americanos, especialmente adolescentes e meninos, desenvolveram o distúrbio dismórfico corporal, representado por uma preocupação excessiva com supostas falhas na aparência, como o tórax pequeno ou o pênis diminuto. Basta, segundo Pope et al. (2000), uma rápida olhada na internet para descobrir o exagero de técnicas de aumento de pênis hoje comercializadas. Essa indústria condiz com uma parte significativa da crescente indústria da imagem corporal masculina, estimulando e aumentando as inseguranças dos homens a respeito dos seus corpos. $\mathrm{O}$ estudo destaca, inclusive, que estes homens, meninos e adolescentes, sofrem silenciosamente, em segredo. Eles não conversam sobre seus problemas, uma vez que, em nossa sociedade, os "homens de verdade" não devem demonstrar preocupação com a aparência, pois podem ser considerados afeminados ou acusados de serem homossexuais.

Para Bourdieu (1999), a estrutura impõe suas pressões aos dois termos da relação de dominação, portanto aos próprios dominantes, que são "dominados por sua dominação", fazendo um esforço desesperado, e bastante patético, mesmo em sua triunfal inconsciência, que todo homem tem que fazer para estar à altura de sua ideia infantil de homem. A preocupação dos rapazes e homens brasileiros com a altura, força física, medida do tórax, potência, poder, virilidade e, particularmente, com o tamanho do pênis pode ser vista como exemplo desta dominação que o dominante também sofre.

Já na década de 1980, o antropólogo Gilberto Freyre, como sempre de forma pioneira e polêmica, buscou pensar o corpo e o comportamento da mulher brasileira. Em seu livro Modos de homem, modas de mulher, Freyre afirmava que a "mulher tende a ser, quanto a modas para seus vestidos, seus sapatos, seus pen- 
teados, um tanto maria-vai-com-as-outras. Isto corresponde ao que a moda tem de uniformizante" (Freyre, 1987: 33). Gilberto Freyre apontava como modelo de beleza brasileira a atriz Sônia Braga: baixa, pele morena, cabelos negros, longos e crespos, cintura fina, bunda ("ancas") grande, peitos pequenos. Freyre (1987) dizia, com certo tom de crítica, que este modelo de brasileira estava sofrendo um impacto norte-europeizante ou albinizante, ou ainda ianque, com o sucesso de belas mulheres como Vera Fischer: alta, alva, loira, cabelos lisos (arianamente lisos), com um corpo menos arredondado.

Este modelo de beleza ianque ganhou muito mais força nas últimas décadas. A revista Veja (2000) publicou uma matéria que dizia "As brasileiras não ficam velhas, ficam loiras", mostrando que a brasileira é uma das maiores consumidoras de tintura de cabelo em todo o mundo. Além de Vera Fischer, que permanece um ideal de beleza, as apresentadoras de programas infantis e, posteriormente, Gisele Bündchen tornaram-se modelos a serem imitados pelas brasileiras; ícones norteeuropeizantes, diria Freyre (1987).

Gilberto Freyre enaltecia o corpo da mulher brasileira, miscigenado, um corpo equilibrado de contrastes (1987). Ele propunha uma consciência brasileira, dizendo que a mulher brasileira deveria seguir modas adaptadas ao clima tropical em vez de seguir passivamente e, por vezes, grotescamente modas de todo europeias ou norte-americanas: na roupa, no sapato, no adorno, no penteado, no perfume, no andar, no sorrir, no beijar, no comportamento, no modo de ser mulher. Eu ainda acrescentaria, no corpo.

Freyre (1987) sugeria que as modas e os modismos não diziam respeito apenas às roupas ou penteados, mas também poderiam se tornar modas de pensar, de sentir, de crer, de imaginar e assim, subjetivas, influírem sobre as demais modas. Ele apontou os excessos cometidos pelas brasileiras mais inclinadas a seguir as modas, especialmente "as menos jovens, para as quais, modas sempre novas surgiriam como suas aliadas contra o envelhecimento" (Freyre, 1987: 25). Gilberto Freyre, duas décadas atrás, admitia que várias novidades no setor de modas de mulher tendem a corresponder a "esse desejo da parte das senhoras menos jovens: o de rejuvenescerem” (Freyre, 1987: 25). E a verdade, dizia ele, é que há sempre modas novas que concorrem para o rejuvenescimento de tais aparências, favorecido notavelmente por cosméticos, tinturas e cirurgias plásticas.

Um estudo muito interessante para discutir a especificidade do corpo brasileiro é o do antropólogo francês Stéphane Malysse, publicado no livro Nu e vestido (Goldenberg, 2002). Ao comparar o corpo da mulher brasileira com o da francesa, Malysse (2002) constatou que na França a produção da aparência pessoal continua centrada essencialmente na própria roupa; já no Brasil é o corpo que está no centro 
das estratégias do vestir. As francesas procuram se produzir com roupas cujas cores, estampas e formas reestruturem artificialmente seus corpos, disfarçando algumas formas (particularmente as nádegas e a barriga) graças ao seu formato. Por outro lado, as brasileiras expõem o corpo e frequentemente reduzem a roupa a um simples instrumento de sua valorização: em uma espécie de ornamento.

Dentro dessa lógica, a tendência das adolescentes francesas é a de se vestirem como suas mães, enquanto no Brasil a tendência é a de a mãe se vestir como a filha para parecer mais jovem. Em algumas das famílias que pesquisei na cidade do Rio de Janeiro, mães, filhas (e algumas vezes as avós) usavam a mesma roupa e os mesmos acessórios. Em uma delas, a mãe e a avó pediam emprestadas as roupas da filha e da neta adolescente. O que confirma uma ideia central de Gilberto Freyre (1987), a de que as modas surgem visando uma preocupação central da mulher brasileira: permanecerem jovens.

\section{O CAPITAL MARITAL}

Logo após retornar de uma viagem pela Alemanha, em junho e julho de 2007, onde ministrei conferências e palestras em diferentes universidades com o título " $\mathrm{O}$ corpo como capital na cultura brasileira", iniciei uma pesquisa na cidade do Rio de Janeiro com mulheres na faixa etária de 50 a 60 anos. Comparando o discurso das cariocas pesquisadas com o de algumas mulheres que entrevistei na Alemanha, da mesma faixa etária, pude perceber algumas questôes interessantes.

Em primeiro lugar, a ênfase na decadência do corpo e na falta de homem é uma característica marcante do discurso das brasileiras. Muitas disseram que passaram a se sentir invisíveis depois dos 50 por não receberem mais elogios ou por não serem paqueradas na rua. Algumas relataram, com tristeza, que "ninguém mais me chama de gostosa”. A ideia de invisibilidade, e também a de aposentadoria da vida sexual e afetiva, esteve muito presente no discurso das brasileiras pesquisadas.

Já as alemãs, ao contrário, enfatizaram a riqueza do momento que estão vivendo em termos de realizaçôes profissionais, afetivas, intelectuais e culturais. Disseram que consideram uma "falta de dignidade" uma mulher querer parecer mais jovem ou se preocupar em "ser sexy", uma infantilidade incompatível com a maturidade esperada nesta idade. A aparência jovem não é tão valorizada por elas e, sim, a experiência de vida, a personalidade, a realização profissional, a saúde e a qualidade de vida. Algumas alemãs me disseram que não compreendem por que tantas brasileiras gostam de receber cantadas na rua e serem chamadas de gostosas. Uma me disse, enfaticamente, que "você mesma é que deve se sentir atraente. Você 
não precisa de ninguém para dizer se é sexy ou não. É muito infantil esta postura. Eu sei avaliar se sou atraente ou não. É só me olhar no espelho. É uma falta de dignidade ser tão dependente do olhar dos homens".

Em minha observação comparativa inicial destes dois universos, as alemãs me pareceram muito mais confortáveis com o próprio envelhecimento do que as brasileiras. Na Alemanha, observei mulheres que parecem muito poderosas objetivamente (em suas profissões e relações afetivas), mas, também, subjetivamente. No Brasil, tenho constatado um abismo enorme entre o poder objetivo das mulheres pesquisadas, o poder real que elas conquistaram em diferentes domínios (sucesso, dinheiro, prestígio, reconhecimento e, até mesmo, a boa forma física) e a miséria subjetiva que aparece em seus discursos (decadência do corpo, gordura, flacidez, doença, medo, solidão, rejeição, abandono, vazio, falta, perda e invisibilidade). Observando-se a aparência das alemãs e das brasileiras pesquisadas, as últimas parecem ser muito mais jovens e em boa forma do que as primeiras, mas se sentem subjetivamente muito mais velhas e desvalorizadas do que elas. A discrepância entre a realidade objetiva e os sentimentos subjetivos das brasileiras me fez perceber que o envelhecimento é um problema muito maior. Isto explicaria os sacrifícios que muitas fazem para parecer mais jovens, por meio do corpo, da roupa e do comportamento. Elas constroem seus discursos enfatizando as perdas que vivenciam e não suas conquistas objetivas. Em uma cultura como a brasileira, em que o corpo é um importante capital, o envelhecimento parece ser vivido como um momento de grandes perdas.

Diferentemente das alemãs, as brasileiras centram o seu discurso na figura masculina. Repetem, insistentemente, que "falta homem no mercado". As que se mostraram mais satisfeitas com suas vidas, entre as brasileiras pesquisadas, são aquelas casadas há muitos anos. Apesar de afirmarem que estão muito satisfeitas, disseram que seus maridos são completamente dependentes, acomodados, inseguros e infantis. $\mathrm{O}$ interessante é que, em quase todos os casos, o marido é o principal provedor da família, tendo um salário muito superior ao da esposa.

A partir dos depoimentos das participantes, constata-se a existência de uma riqueza extremamente valiosa para as brasileiras: o marido. Ter um marido, um casamento considerado sólido e satisfatório é considerado um verdadeiro capital para as brasileiras. Elas se sentem duplamente poderosas, pois, além de terem um marido, acreditam que são mais fortes, independentes e interessantes do que ele. Em um mercado de casamento em que os homens são escassos, principalmente na faixa etária pesquisada, as casadas sentem-se poderosas por terem um produto raro e altamente valorizado por outras mulheres. Também se sentem superiores, únicas e imprescindíveis para os seus maridos. Com certeza, seria mais adequado chamar 
esta riqueza que parece ser tipicamente brasileira, ao menos quando comparada ao que as alemãs valorizam, de capital maridal. Mas, mesmo perdendo um pouco da precisão da ideia, parece mais elegante denominá-la de capital marital.

\section{Desejos Íntimos}

Na pesquisa com indivíduos das camadas médias da cidade do Rio de Janeiro, quando perguntados sobre "Quais os principais problemas que você vive ou viveu em seus relacionamentos amorosos?" homens e mulheres responderam, em primeiro lugar: "ciúmes e infidelidade". No entanto, a principal queixa masculina foi, basicamente: "falta de compreensão". Já as mulheres responderam: "falta de intimidade, egoísmo, incompatibilidade de gênios, falta de segurança, falta de confiança, falta de sinceridade, falta de diálogo, falta de liberdade, falta de paciência, falta de atenção, falta de companheirismo, falta de maturidade, falta de amor, falta de carinho, falta de tempo, falta de tesão, falta de respeito, falta de individualidade, falta de dinheiro, falta de interesse, falta de reciprocidade, falta de sensibilidade, falta de romance, falta de intensidade, falta de responsabilidade, falta de pontualidade, falta de cumplicidade, falta de igualdade, falta de organização, falta de amizade, falta de alegria, falta de paixão, falta de comunicação, falta de conversa”. Algumas ainda afirmaram que falta tudo. Enquanto os homens foram extremamente objetivos e econômicos em suas respostas, algumas mulheres chegaram a anexar e grampear folhas ao questionário para acrescentar mais e mais faltas.

As mulheres queixam-se de que não conseguem ter intimidade com os maridos ou namorados. No entanto, quando pergunto para os homens, eles acham que têm intimidade com suas parceiras por compartilharem momentos como: fazer sexo, beijar, carinhos, ficar nu. Para eles, a intimidade é da ordem do corporal, do toque, da visão. É uma intimidade sexual. É uma intimidade física.

Elas reagem: esta não é a verdadeira intimidade, não é uma intimidade íntima. Intimidade, para elas, é um tipo muito particular de estar juntos, de conversar, de escutar, de compartilhar o silêncio, um nível mais profundo de comunicação psicológica. É uma intimidade emocional.

Para eles, a intimidade tem gradações, níveis, escalas. Eles podem ter mais ou menos intimidade, pouca ou muita intimidade, falar de um problema com alguns familiares e de outro com amigos. Eles hierarquizam e medem a intimidade que têm com as pessoas, classificam com quem podem (ou não) falar sobre mulheres, trabalho, futebol, política etc. É uma intimidade repartida, partida. Para alguns homens, a intimidade é da ordem do segredo, do que pode ser dito apenas para 
aqueles em quem confiam (pais, irmãos, esposa, namorada, amigos) ou do que não pode ser dito para ninguém: “é algo só meu, do meu interesse”. Muitos disseram que só têm intimidade total consigo mesmos, isto é, que existem coisas que só podem e devem ser ditas para si. Coisas que não interessam a mais ninguém, que devem ser guardadas, reservadas, protegidas.

Alguns homens disseram que, quando estão com problemas no trabalho ou com a mulher, desabafam com o amigo que diz: "vamos beber". Consideram que assim conseguem esquecer o problema que, efetivamente, passa. Já as mulheres ruminam por muito tempo os seus problemas. Repetem exaustivamente os mesmos problemas sem buscarem uma solução. Nenhuma disse que adota a estratégia do "vai passar, vamos beber e esquecer".

Os homens querem esquecer, as mulheres relembram incessantemente. Eles querem resolver o problema, de preferência muito rapidamente. Elas querem refletir sobre o problema, sem necessariamente resolvê-lo. Os familiares e amigos íntimos são fundamentais para reforçar tanto a postura de resolver como a de refletir sobre os problemas. Os homens têm uma visão prática da intimidade. É uma intimidade objetiva. Já as mulheres têm uma percepção reflexiva da intimidade. É uma intimidade subjetiva.

Para as mulheres, a intimidade parece estar relacionada a uma forma específica de conversar, não ao seu conteúdo. É uma intimidade sem gradação, nível, escala. Ou se tem, ou não se tem intimidade. É uma intimidade única. É um jeito de falar sobre si e de ser escutada pelo outro. Sem interferências, sem medo de ser julgada, de ser rejeitada, criticada, ironizada. É um tipo de conversa especial, de entrega singular, de quem fala e de quem escuta. É uma conversa em que existe aceitação, respeito, troca, apoio. Em que os dois podem ser vulneráveis e revelar suas fragilidades e medos. Pode ser uma intimidade silenciosa. O importante é que não exista ruptura, ruído, atrito neste tipo de encontro. Ela é singular, especial, a dois. Não necessita de um tópico especial ou de um segredo. É um jeito muito particular e valorizado de falar e, principalmente, de ser escutado. O outro deve ser maleável, flexível, adaptável, para saber como ser passivo e simplesmente escutar sem interferir, ou, quando necessário, ser ativo e dar algum tipo de resposta. Um nível profundo e psicológico de comunicação e de reciprocidade. É a intimidade íntima. Coisa que, elas dizem, os homens são incapazes de compreender.

É possível perceber que as mulheres falam de si mesmas como superiores aos homens neste domínio tão valorizado por elas e pouco elaborado na vida deles. Elas se consideram mais sensíveis, maduras e profundas do que eles, que são vistos como mais carnais, físicos, sexuais. A intimidade intima parece ser um 
privilégio e, também, um poder feminino. O que mostra que as mulheres podem exercer dominação exatamente nos domínios em que constroem e hierarquizam diferenças de gênero. Domínio em que os homens são esmagados pela superioridade feminina.

É interessante pensar que esta onipresença da ideia de intimidade nas minhas pesquisas pode ser parte de um discurso de dominação que legitima o poder feminino em tudo o que se relaciona ao mundo privado, ao mundo das emoções, dos sentimentos e das relaçôes entre os gêneros.

Em um dos meus grupos de pesquisa, uma viúva de 68 anos me disse que está muito feliz, pois namora um homem bem mais jovem do que ela. Ele tem 40 anos e é casado com uma mulher de 32. Ela contou que eles se encontram quase todos os dias da semana, sempre na hora do almoço.

Ele diz que está comigo porque sou carinhosa, compreensiva, alegre. Ele me chama de sweetheart. Reclama que a mulher dele é muito mandona, briga muito, exige demais. Ele morre de medo dela. Sabe como ele chama a mulher? Bruxa, megera... Ele sente falta de carinho, quer alguém que cuide dele, que o admire. Sei que não é por falta de opção que ele está comigo. Então, eu capricho. Estou sempre cheirosa e arrumada, sou muito carinhosa e atenciosa, faço massagem nos pés dele, preparo comidinhas gostosas, sou compreensiva, digo que ele é o melhor amante do mundo. Não cobro nada, não reclamo de nada. E ele sempre volta para mim.

Após um debate sobre a infidelidade nos casamentos contemporâneos, uma mulher me disse: "você tem que me entrevistar. Eu tenho uma Outra". Ela contou que é casada há dez anos, tem dois filhos e que sempre achou, e ainda acha, que é $100 \%$ heterossexual. Mas disse que está apaixonada por uma amiga que consegue lhe dar tudo o que falta na relação com o marido: atenção, carinho, delicadeza, diálogo, amizade e, especialmente, longos e deliciosos momentos de intimidade física e emocional.

Sou heterossexual. Só que nunca consegui ter a intimidade que tanto desejo com um homem. Eles não sabem dar um abraço aconchegante ou escutar verdadeiramente uma mulher. $\mathrm{O}$ sexo com minha amiga é consequência de horas e horas de intimidade. Só com ela consegui ter a intimidade que sempre busquei. Nunca me senti tão próxima de um homem, nunca me senti tão escutada por um homem. Acho que os homens são completamente ignorantes em tudo o que diz respeito à intimidade. 
Os participantes acreditam em naturezas diferentes para homens e mulheres, naturezas que geram dificuldades, conflitos e frustraçõos nas relações amorosas. Uma das maiores insatisfaçôes femininas, entre as inúmeras citadas, é a impossibilidade de experimentar uma verdadeira intimidade com o parceiro. A intimidade, para elas, está associada a uma forma mais profunda de comunicação, de conversa, de diálogo, de escuta; e também a um tipo especial de entrega emocional e amorosa. Elas acreditam que os homens são incapazes de serem mais subjetivos, reflexivos, interiorizados. Acreditam, também, que eles são imaturos, superficiais e alienados; que eles não conseguem expressar seus sentimentos, desejos e sofrimentos como elas.

Nos discursos femininos é possível enxergar a ideia de que a natureza da mulher, em termos de autoconhecimento e de exploração da subjetividade, é superior à masculina. A objetividade, praticidade e racionalidade masculinas, bastante valorizadas em outros contextos, tornam-se impedimentos para um relacionamento íntimo. Elas se sentem lesadas por acreditarem que investem muito mais do que eles nesta busca por intimidade.

Já o discurso masculino revela que eles se sentem injustamente cobrados por não conseguirem corresponder às excessivas cobranças das mulheres. Eles dizem que não se sentem compreendidos ou aceitos por elas, que parecem permanentemente insatisfeitas e não reconhecem seus esforços para responder às ilimitadas e contraditórias demandas femininas.

Chama muita atenção o fato de as mulheres reclamarem da falta de intimidade com seus parceiros, enquanto os homens se queixam da falta de compreensão de suas mulheres. Esta pareceu a diferença de gênero mais marcante entre os pesquisados. Do lado feminino, a ânsia por intimidade. Do masculino, a busca por compreensão. Talvez aqui, neste descompasso entre os desejos femininos e masculinos, esteja a chave para se compreender os atuais conflitos nos arranjos conjugais. Pode-se perceber, nos discursos de homens e mulheres, um verdadeiro abismo entre os gêneros quanto ao valor e ao significado da intimidade e da compreensão nos relacionamentos amorosos.

\section{INVISÍVEIS OU LIVRES?}

Nos grupos de discussão realizados com mulheres cariocas de mais de 40 anos, o que mais se destaca são quatro tipos de ideias, extremamente recorrentes nos depoimentos das pesquisadas: invisibilidade, falta, aposentadoria e liberdade.

Um exemplo da ideia de falta é o seguinte: 
Sei que é o maior clichê, mas é a mais pura verdade: falta homem no mercado. Falta mesmo. Todas as minhas amigas que estão na faixa dos 50 estão sozinhas. Eu não tenho namorado há um tempão. Até saio com uns caras, mas eles querem se fazer de garotôes. É o botox dos homens. Eles se separam e passam a falar, se vestir e se comportar como um garoto. Acho ridículo, até patético. Mas eu queria um namorado, um companheiro. Sinto falta. Meu ex-marido, três meses depois da separação, já estava com uma namorada vinte anos mais nova. Que maluco vai querer uma velha decrépita, ou até mesmo uma coroa enxuta, se pode ter uma jovem durinha com tudo no lugar?

Algumas pesquisadas se excluem do mercado sexual. Elas usam a ideia de aposentadoria em seus depoimentos: "A última vez que eu transei eu devia ter 50 anos. Tem quem queira, mas eu é que não quero. Me aposentei neste setor".

Outras ficam obcecadas com as imperfeições do próprio corpo.

Acabei de fazer 40 anos, isso mudou toda a minha percepção do meu corpo. Passei a enxergar coisas que nunca tinha percebido: celulite, estrias, manchas, rugas. É como se de um dia para outro eu tivesse envelhecido 20 anos. Um dia me sentia jovem, magra, gostosa. Depois de fazer 40 passei a me sentir uma velha caquética, gorda, flácida. Na cama, também tudo mudou. Antes transava de luz acesa, gostava que meus namorados olhassem meu corpo. Agora entro em pânico. Preciso estar com a luz apagada, debaixo do lençol. Não tiro o sutiã para eles não perceberem que o peito está caído. O pior é que sei que eles não estão nem aí para estes detalhes, é tudo paranoia minha.

Muitas mulheres me disseram que passaram a se sentir invisíveis depois dos 40.

Tive muitos namorados até os 40 anos, sempre fui considerada uma mulher sexy. Meu trauma começou quando fiz 40 e namorei um cara de 50 . Ele não me enxergava, passava o tempo todo olhando as bundas e os peitos das garotinhas. Aí comecei a me sentir uma velha, pois me sentia invisível para ele. Aconteceu o mesmo com outros homens. Aqueles olhares, cantadas, elogios que eram tão comuns na minha vida, desde a adolescência até os 40 anos, simplesmente desapareceram. Me acostumei a vida toda a ser chamada de gostosa pelos homens e, de repente, eles me ignoram. Sou uma mulher invisível.

Estes discursos podem ser vistos como uma postura de vitimização das mulheres nesta faixa etária que apontam, predominantemente, as perdas, os medos e as dificuldades associadas ao envelhecimento. Por outro lado, apareceu também, com muita ênfase, a ideia de liberdade. 
Hoje em dia, a minha paz de espírito é a coisa que eu mais prezo. Não quero me chatear com homem. Eu não sabia ser sozinha. Hoje eu sei. Pela primeira vez na minha vida eu me sinto realmente livre.

O casamento me fez virar funcionária pública, achava que tinha estabilidade, segurança e não precisava cuidar dele, nem de mim. O casamento é um tipo de prisão invisível: parece confortável, mas vai te destruindo aos poucos, deixando só o lado desagradável. Pena que eu só descobri a liberdade aos 50. Poderia ter sido antes.

A frase "hoje eu posso ser eu mesma pela primeira vez na minha vida" foi repetida por muitas mulheres que percebem o envelhecimento como uma redescoberta, altamente valorizada, de um "eu" que estava encoberto ou subjugado pelas obrigações sociais, especialmente pelo investimento feito no papel de esposa e de mãe.

É interessante observar que, tanto no discurso de vitimização quanto no de liberação, dois foram os eixos centrais das brasileiras pesquisadas: o corpo e a relação amorosa e sexual. $\mathrm{O}$ corpo foi tanto objeto de extremo sofrimento (em função de suas doenças ou decadência) quanto de extremo prazer (em função da maior aceitação e cuidado com ele). Os parceiros amorosos foram, também, objeto de extrema dor (alcoolismo, machismo, violência, autoritarismo, egoísmo, abandono, rejeição, faltas) ou de extremo prazer (companheirismo, prazer sexual, cumplicidade).

Em uma cultura como a brasileira, em que o corpo e o marido são importantes capitais, o envelhecimento pode ser vivenciado como um momento de perdas e sofrimentos. No entanto, em uma cultura em que a liberdade é o principal valor, o envelhecimento pode ser visto como um momento de novas descobertas, conquistas e realizações.

Simone de Beauvoir escreveu um livro fascinante e cruel sobre o processo de envelhecimento. Em $A$ velhice, publicado em 1970 na França, ela refletiu sobre o próprio sofrimento: "É normal, uma vez que em nós o outro que é velho, que a revelação de nossa idade venha dos outros. Eu estremeci, aos 50 anos, quando uma estudante americana me relatou a reação de uma colega: 'Mas então, Simone de Beauvoir é uma velha!'. Toda uma tradição carregou essa palavra de um sentido pejorativo - ela soa como um insulto" (Beauvoir, 1990: 711).

No entanto, ela sugeriu a possibilidade de uma "bela velhice": construir um projeto singular que torne cada indivíduo autorizado a decidir sobre os seus comportamentos não de acordo com determinadas regras, mas segundo sua própria 
vontade. No caso das mulheres, em particular, "a última idade representa uma liberação: submetidas durante toda a vida ao marido, dedicadas aos filhos, podem enfim preocupar-se consigo mesmas" (Beauvoir, 1990: 711), concluiu a filósofa.

No filme sueco "A vida começa aos 40", a filha exige da mãe recém-separada que pare de dançar, pois considera esta diversão inadequada para uma mulher de sua idade. Acusa a mãe de ser uma velha ridícula. A mãe reage indignada e diz que vai dançar aos 40, 50, 60, 70 e sempre que quiser, pois paga as suas contas e não deve satisfação a ninguém. Diz que é ela, e não os outros, quem irá decidir o que pode ou o que não pode fazer.

Entrevistando brasileiras de mais de 40 anos, encontrei esta mesma ideia. Casadas ou separadas, com filhos ou netos, com namorados ou sozinhas, trabalhando ou aposentadas, as mulheres com quem tenho conversado dizem categoricamente: "é a primeira vez na vida que me sinto realmente livre. Antes, vivia para o marido, os filhos, a família. Já cumpri todas as minhas obrigações sociais e familiares. Agora, posso cuidar de mim, fazer o que realmente gosto, não dar mais satisfação para ninguém. Posso ser eu mesma pela primeira vez na minha vida”.

Quando penso na "bela velhice", penso na geração que foi jovem nos anos 1960 e que está começando a envelhecer. Geração que reinventou a sexualidade, o corpo, as novas formas de casamento e de família. Geração que teve como centro a busca do prazer e da liberdade sexual, a recusa de qualquer forma de controle e de autoridade e a defesa da igualdade entre homens e mulheres. Geração que não aceitará o imperativo "seja um velho!" ou qualquer outro tipo de rótulo que sempre rejeitou e contestou.

\section{REFERÊNCIAS}

Beauvoir, S. (1990). A velhice. Rio de Janeiro: Nova Fronteira.

Bourdieu, P. (1999). A dominação masculina. Rio de Janeiro: Bertrand Brasil.

Bourdieu, P. (2007). A distinção. São Paulo: Edusp; Porto Alegre: Zouk.

Freyre, G. (1987). Modos de homem, modas de mulher. Rio de Janeiro: Record.

Freyre, G. (2000). Entrevista dada a Veja, <www.veja.com.br>, em 07/06/2000.

Goldenberg, M. (2002). Nu \& vestido: dez antropólogos revelam a cultura do corpo carioca. Rio de Janeiro: Record.

Goldenberg, M. (2006). O corpo como capital: para compreender a cultura brasileira. Arquivos em movimento, 2, 115-123.

Goldenberg, M. (org.). (2007). O corpo como capital. São Paulo: Estação das Letras e Cores. 
Goldenberg, M. (2008). Coroas: corpo, envelhecimento, casamento e infidelidade. Rio de Janeiro: Record.

Malysse, S. (2002). Em busca dos (h)alteres-ego: olhares franceses nos bastidores da corpolatria carioca. In: M. Goldenberg (org.). Nu \& vestido: dez antropólogos revelam a cultura do corpo carioca (pp. 79-137). Rio de Janeiro: Record.

Mansur, A. (2002). O corpo que eles desejam... não é o que elas querem ter. Revista Época. Retirado de <http://revistaepoca.globo.com/Revista/Epoca/0,,EMI31695-15228,00. html>.

Pope, H. G., Phillips, K. A., \& Olivardia, R. (2002). O complexo de Adônis: a obsessão masculina com o corpo. Rio de Janeiro: Campus.

Aceito para publicação em 28 de outubro de 2010 